\title{
O Papel da Infraestrutura no Combate aos llícitos Transfronteiriços na América do Sul
}

\section{The Infrastructure's Role in Combating Cross-Border Ilicits in South America}

Rev. Bra. Est. Def. v. 3, nº 1, jan./jun. 2016, p. 139-152

ISSN 2358-3932

\section{NAIANE INEZ COSSUL BRUNA COELHO JAEGER}

\section{INTRODUÇÃO}

O presente artigo tem como objetivo demonstrar como a infraestrutura sul-americana exerce papel fundamental na coibição dos crimes transfronteiriços na América do Sul, baseada no trinômio monitoramento/controle, mobilidade e presença. Por infraestrutura, entende-se o aparato de estruturas físicas no âmbito dos transportes, energia e comunicações. Ressalta-se a importância do papel dual da infraestrutura, ou seja, seus benefícios servem igualmente a propósitos civis e militares, cujos efeitos se alastram por todos as esferas da sociedade.

Para a consecução do objetivo, inicialmente delineia-se um panorama dos ilícitos que impactam a região, especialmente o tráfico de drogas e de armas, apontando a facilidade com que transitam pelas fronteiras brasileiras. Na sequência, observa-se a importância da infraestrutura regional, como mecanismo de combate a esses ilícitos, atrelada diretamente às questões de defesa nacional, uma vez que a infraestrutura de uso dual, com potencial para servir a fins civis e militares, é estratégica para a região. Demonstra-se, assim, como a infraestrutura capacita a vigilância e a atuação na faixa de fronteira. Por fim, evidenciam-se os projetos em andamento, especialmente o Sistema Integrado de Monitoramento de Fronteiras (SISFRON), com a fase-piloto já em funcionamento em Dourados (MS), no espaço centro-oeste brasileiro, cobrindo a fronteira com o Paraguai e a Bolívia. Esse projeto, através da infraestrutura de sensoriamento, antenas de comunicação, rada-

Naiane Inez Cossul - Doutoranda do Programa de Pós-Graduação em Estudos Estratégicos Internacionais da Universidade Federal do Rio Grande do Sul. E-mail: naianecossul@hotmail.com.

Bruna Coelho Jaeger - Doutoranda do Programa de Pós-Graduação em Estudos Estratégicos Internacionais da Universidade Federal do Rio Grande do Sul. E-mail: naianecossul@hotmail.com. 
res, satélites e centros de comando e controle, permite monitorar as principais vias de entrada de ilícitos, garantir a presença do Estado em áreas remotas, projetar cooperação regional para o compartilhamento de dados e dar suporte à atuação conjunta entre os países e Forças sul-americanas.

\section{PANORAMA DOS ILÍCITOS TRANSFRONTEIRIÇOS NA AMÉRICA DO SUL}

Objetiva-se, nessa seção, trazer a definição e o panorama dos ilícitos transnacionais na América do Sul, bem como a caracterização da faixa de fronteira ${ }^{1}$ que, devido aos seus aspectos peculiares, permite a fácil atuação desses crimes e exige mecanismos para adequar a defesa a essas fontes de insegurança não tradicionais. Assim, o conceito de ilícitos transnacionais, elencado no Livro Branco de Defesa Nacional do Brasil (2012: 263), faz menção a dois grandes campos: o dos crimes contra a pessoa, envolvendo o narcotráfico, o tráfico de armas e munições, o tráfico de pessoas; e o dos crimes financeiros, como a lavagem de dinheiro e a corrupção. Esses novos temas, ou novas formas de abordar temas tradicionais, trazem implicações para a proteção da soberania - ocorrem nas faixas de fronteira, ambiente estratégico e diretamente ligado à defesa nacional - e geralmente em locais onde o Estado não consegue estender suas políticas, permitindo espaços de vulnerabilidades.

Os ilícitos transfronteiriços geram externalidades negativas em todos os países sul-americanos. Por serem comuns e compartilhados por esses Estados, e possuírem características bastante similares na atuação em cada país, é possível afirmar que constituem um problema de segurança regional. Nesse sentido e como afirma Dreyfus (2009: 184) já não existem países produtores, de trânsito ou de consumo de ilícitos - todos os países sul-americanos enquadram-se nessa problemática. Portanto, de acordo com a ideia de Masón (2000: 83) o entrelaçamento entre a ordem internacional e a doméstica do pós-Guerra Fria fez com que os desenvolvimentos securitários de um terreno se transpusessem facilmente a outro, desafiando as fronteiras territoriais, adentrando Estados vizinhos e impactando a segurança regional.

Houve, de certa maneira, uma relativização dos problemas tradicionais de segurança e defesa para os não tradicionais, no sentido de que os ilícitos passaram a assumir um lugar de destaque nas políticas sul-americanas e nos quais não cabe mais utilizar soluções tradicionais via uso da força. São problemas de segurança que não estão tensionados, todavia, exigem uma reestruturação de infraestrutura tecnológica para atuar no combate e monitoramento. Fazem parte da "transversalidade dos temas de segurança e de defesa” (LBDN 2012: 32) e exigem, cada vez mais, formas integradas de combate e alocação de recursos por parte dos governantes. 
Congrega-se, na região sul-americana, um panorama de que "poucas atividades econômicas cresceram e se desenvolveram tanto quanto as conduzidas pelo crime organizado" (Sain, Games 2014: 119), no qual inclui-se o tráfico de drogas e armas. Nesse panorama, o narcotráfico atua como dinamizador dos ilícitos transnacionais na América do Sul, uma vez que "a maior parte destas atividades do crime organizado se desenvolveram sob o amparo do principal negócio ilegal na região" (Sain, Games 2014: 129) e tendo em vista também que "o narcotráfico se destaca como a manifestação mais desenvolvida do crime organizado na região (Sain, Games 2014: 129). Dessa maneira, os ilícitos transnacionais, pautados nas novas ameaças, cada vez dinamizam mais as faixas de fronteira, sendo os países sul-americanos expressivos no que se refere às atividades ilícitas transnacionais, isso se deve ao compartilhamento de fronteiras e a complementariedade entre oferta e demanda de produtos e serviços ilegais (Pereira 2013: 8). ${ }^{2}$

Portanto, como aponta Vaz (2002: 4), as áreas de fronteira sul-americanas congregam características e problemas comuns associadas à "desocupação, à escassa presença do Estado e acumulação de problemas sociais […], ao déficit de desenvolvimento, de oferta de serviços públicos e, consequentemente, à falta de assistência às populações [...]”. O contexto ao qual esses fatores estão ligados gerou, historicamente, não só na faixa fronteiriça, mas dentro de Estados um quadro propício à implantação e florescimento de atividades informais e criminosas - "questões que desafiam a segurança, sem, contudo, representarem ameaças militares” (Vaz 2002).

Os cerca de $17 \mathrm{mil} \mathrm{km}$ de fronteiras possuem características comuns, entre elas os fatores geográficos que dificultam a implementação de políticas públicas na região fronteiriça e que são determinantes no estabelecimento de infraestrutura, gerando dificuldade para o acesso local e para a própria construção civil (Oliveira 2014: 8). Além disso, aproximadamente 12 mil km correspondem à fronteira da Amazônia Legal, sendo que a região Norte equivale a mais da metade do território brasileiro e se caracteriza, entre outros dados, por possuir baixa densidade populacional e extensa faixa de fronteira (LBDN 2012: 19).

Assim, tendo em vista que a região de fronteira é porosa, pouco densa e que, cada vez mais, os ilícitos utilizam-se desse espaço, tornam-se necessários mecanismos eficazes de combate que utilizem tecnologia de monitoramento, uma vez que a presença física é dificultada devido às características mencionadas. O panorama dos ilícitos transnacionais na América do Sul sugere, portanto, a necessidade de infraestrutura voltada a essas necessidades. O SISFRON, é, desta forma, um mecanismo para adequar a defesa a essas novas fontes de insegurança. É uma tentativa de resposta a essas novas dinâmicas. 


\section{INFRAESTRUTURA COMO FATOR PARA A DEFESA NACIONAL E A SEGURANÇA REGIONAL}

Nos últimos anos, o Brasil vem empreendendo um processo de modernização de suas capacidades defensivas. A Estratégia Nacional de Defesa (2008), o Livro Branco de Defesa Nacional (2012) e outros esforços legislativos do Congresso Nacional representam a percepção brasileira de que é preciso adaptar-se à nova geopolítica internacional. O processo de integração regional, vertebrado pelo Brasil, configura-se como um dos aspectos principais dessa nova orientação. A integração infraestrutural, nesse contexto, aparece como um elemento fundamental para a consolidação dessas capacidades defensivas. Especialmente, pois incide sobre a logística do país, entendida neste trabalho como todas as atividades que são pré-condições ao uso da força, ou seja, que permitem a condução da guerra e tornam-se uma preocupação tática ou estratégica, já que afetam a capacidade de engajamento em uma conflagração (Proença Jr., Duarte 2005).

Em 2008, a partir do Decreto $n^{\circ}$ 6.592, o Brasil regulou a Mobilização Nacional e estabeleceu o Sistema Nacional de Mobilização. Esse decreto estabelece "como logística nacional o conjunto de atividades relativas à previsão e provisão dos recursos e meios necessários à realização das ações decorrentes da Estratégia Nacional de Defesa" (Brasil, Presidência da República 2008). O Sistema Nacional de Mobilização (SINAMOB) é responsável por organizar esse processo, integrando os diferentes órgãos envolvidos. Para executá-la, algumas medidas são previstas, tais como a reorientação da produção industrial e agrícola, comercialização, distribuição e consumo dos bens e de serviços. Esse processo geraria impactos negativos na sociedade (como escassez de produtos, inflação), o que poderia ser mitigado pela construção de infraestrutura regional.

Primeiramente, a integração sul-americana viabiliza a diminuição dos custos industriais, o que permite o investimento em inovação tecnológica - processo central para a consolidação de uma indústria de defesa no país. Ademais, em tempos de guerra, os vizinhos sul-americanos poderiam colaborar mais facilmente com o suprimento das necessidades do Brasil perante uma agressão externa. Especialmente, se a integração infraestrutural for bem-sucedida, pois ampliaria a integração da cadeia energética e produtiva, conforme afirma Carvalho (2011):

[...] a integração sul-americana se apresenta como importante alternativa para fortalecer o poder nacional em tempos de paz, pelo incremento da economia, ampliação da demanda intrarregional, fortalecimento do setor produtivo e pela diversificação tecnológica e industrial. Em caso de Mobilização Nacional, esta integração poderá minimizar os impactos 
econômicos e sociais, beneficiando-se de produtos e serviços provenientes de países vizinhos que poderão atender às demandas crescentes e contribuir para a estabilidade interna e o bem-estar da população durante um eventual período de conflito (Carvalho 2011: 79).

A busca brasileira por liderar o processo de integração regional não representa um empecilho ao desenvolvimento dos países vizinhos. Pelo contrário, são promovidos de forma mútua. Contudo, a postura brasileira não se dá devido a um caráter altruísta do país, mas sim decorrente de um cálculo estratégico que visa diminuir a influência externa no subcontinente e aumentar a confiança dos vizinhos. Com isso, o Brasil caminha rumo a uma elevação do seu nível de projeção internacional ao mesmo tempo em que garante maior estabilidade no seu entorno imediato (Couto 2013).

Segundo a CEPAL (2012), existe uma clara relação entre aumento dos serviços de infraestrutura e aumento do desenvolvimento econômico e social. Além disso, há uma a relação positiva entre a diminuição da desigualdade de renda e a disponibilidade de infraestrutura. ${ }^{3}$ Dessa forma, é possível compreender como essa relação entre desenvolvimento e infraestrutura pode impactar sobre a segurança regional sul-americana. As assimetrias regionais, especialmente no interior do subcontinente, representam as maiores causas para potenciais conflitos entre os vizinhos. O Brasil, sendo a maior economia da América do Sul, precisa garantir um entorno estável e desenvolvido para que sua própria inserção internacional possa atingir o patamar desejado para o século XXI. O Livro Branco de Defesa Nacional (2012) aponta a América do Sul como entorno imediato estratégico para o Brasil, cuja segurança e defesa são indissociáveis à estabilidade de suas fronteiras. Tensões políticas ou securitárias nos vizinhos trazem instabilidade para a integração e para o controle de fronteiras, tal como o conflito das FARC na Colômbia, o qual gerou uma crise na região Amazônica com a ampliação das atividades ligadas ao narcotráfico e tráfico de armas.

Nesse sentido, a integração infraestrutural incide diretamente sobre a geopolítica regional. Na medida em que influencia a capacidade logística do Brasil, facilita a mobilização do país em face de uma agressão externa, bem como o monitoramento de ilícitos através das tecnologias de comunicação. Ademais, há uma relação direta entre infraestrutura, desenvolvimento e resolução de conflitos, visto que a redução de assimetrias regionais através do investimento em infraestrutura tende a diminuir a propensão a tensões entre vizinhos e dentro dos próprios países.

Por conseguinte, para que a América do Sul se constitua como um polo de poder no século XXI é crucial que a região esteja fortalecida e preparada para as crescentes disputas globais. Nesse sentido, a integração regional apresenta-se como a melhor alternativa para garantir que o subcontinente 
sul-americano se torne uma unidade caracterizada por autonomia, cooperação e paz. A América do Sul é uma das regiões do mundo com maiores quantidades de recursos naturais estratégicos, cuja proteção representa um enorme desafio. Desafio, pois provocam a avidez de muitos países devido à escassez de recursos naturais e energéticos. $\mathrm{O}$ "cordão de pérolas" britânico no Atlântico Sul, as bases estadunidenses na Colômbia e no Paraguai, as ilhas Malvinas e a Guiana Francesa demonstram que a região deve estar preparada ante ameaças extrarregionais que já se encontram bastante próximas. Por outro lado, como nunca antes, representam uma oportunidade para que os países sul-americanos aproveitem o contex to regional de aproximação e de objetivos em comum para empreender uma verdadeira integração. Nesse sentido, muitos avanços têm sido realizados na última década, entretanto, precisam transcender os objetivos pontuais e transitar para uma integração planejada de forma estratégica.

Para tanto, a infraestrutura aparece como elemento crucial. A integração física na América do Sul é o elemento que pode vincular de forma definitiva os países ao processo, sobrevivendo a mudanças políticas, visto que é virtualmente irreversível. A promoção de infraestrutura integrada na América do Sul é um importante fator para garantir maior segurança e capacidades de defesa, bem como para impulsionar o desenvolvimento socioeconômico e aumentar a presença do Estado em regiões isoladas. Nesse sentido, a construção de grandes obras de energia, transportes e comunicações constitui-se como um fator significativo para aumentar as capacidades logísticas da região, formar cadeias produtivas e reduzir as assimetrias existentes, especialmente no interior do subcontinente. O progresso impulsionado pela integração infraestrutural, além de consolidar o processo de união, habilita a América do Sul como um importante ator no Sistema Internacional. Somente o seu fortalecimento de forma autônoma e integrada pode garantir que o subcontinente sul-americano se mantenha, relativamente, como uma zona de paz. Nesse contexto, a liderança brasileira é fundamental para assegurar os avanços pretendidos e possibilitar que essa oportunidade histórica não seja perdida como no passado, garantindo um futuro integrado à América do Sul.

\section{SISTEMA INTEGRADO DE MONITORAMENTO DE FRONTEIRAS - SISFRON}

Importa para essa seção o entendimento do SISFRON como um projeto que alia infraestrutura e tecnologia, a fim de conformar um trinômio de monitoramento/controle, mobilidade e presença para, entre outras funções, coibir os ilícitos transnacionais. Diante da importância da infraestrutura regional, elencada na seção anterior, observa-se que em paralelo 
ao Plano Estratégico de Fronteiras, ${ }^{4}$ vem ocorrendo o desenvolvimento de projetos na Marinha, no Exército e na Aeronáutica e merecem destaque por terem atuação ligada às fronteiras e ao sistema de monitoramento e controle: o Sistema de Gerenciamento da Amazônia Azul (SisGAAz), o Sistema Integrado de Monitoramento de Fronteiras (SISFRON), o Sistema de Controle do Espaço Aéreo Brasileiro (SISCEAB) e o Sistema de Defesa Aeroespacial Brasileiro (SISDABRA) - projetos que estão em desenvolvimento e que, no futuro, se forem interligados, farão a vigilância preventiva de todo o território nacional.

Destaca-se o SISFRON que, dentre esses projetos, está ligado diretamente às fronteiras terrestres brasileiras, local onde há a maior incidência de crimes transnacionais. Sob responsabilidade do Exército, é um sistema de monitoramento, com a fase-piloto já em funcionamento em Dourados (MS), no centro-oeste brasileiro, cobrindo a fronteira com o Paraguai e a Bolívia. Segundo Leite (2013: 12), "a localização do projeto-piloto levou em consideração as principais vias de entrada de contrabando em nosso país, principalmente de drogas e armas [...]”. Além disso, a fase-piloto conta com antenas de comunicação, infovia (linha digital para redes eletrônicas), radares, sensores eletromagnéticos, componentes táticos e de comunicação satelital, e centros de comando e controle (Brasil, Ministério da Defesa 2014) e em etapas posteriores, contará com o sistema de drones. Com as informações colhidas será possível acionar as unidades operacionais para agir em tempo real.

O SISFRON, através do trinômio monitoramento/controle, mobilidade e presença, quando completamente instalado, será responsável pelo monitoramento de toda a fronteira brasileira com os dez países sul-americanos através de instalação de bases móveis, radares, sensores, comunicação integrada e criptografada, desenvolvimento de softwares e infraestrutura para monitorar e vigiar (Brasil, Ministério da Defesa 2015) e será um mecanismo importante para auxiliar o combate ao tráfico de drogas e armas nas fronteiras do Brasil. Segundo o ex-Ministro da Defesa, Celso Amorim, na ocasião da visita as instalações do projeto-piloto, o SISFRON “[ [...] é fundamental do ponto de vista não só da defesa, mas também do combate aos ilícitos e ao crime organizado" (Brasil, Exército Brasileiro 2014). ${ }^{5}$

Assim, essa nova demanda de segurança, por parte dos ilícitos, gera processos complexos, difíceis de responder e dimensionar, onde as análises de segurança nacional e internacional são interconectadas, ao passo que, como aponta Vaz (2002:1), "as ameaças potenciais não emanam de políticas de Estado e expressam-se sob formas não tradicionais e associadas a problemas, em grande medida, enraizados nas estruturas domésticas" - e com isso a dificuldade de abordá-los exclusivamente em torno das considerações de disputa de poder. 
Dessa forma, com a criação do Plano Estratégico de Fronteiras houve uma reestruturação da concepção de fronteira, pois altera o histórico de intervenção fragmentada e pontual para uma percepção integrativa, cooperativa e articulada entre municípios, estados e países fronteiriços. Além disso, gera o consequente fortalecimento e consolidação da própria presença do Estado brasileiro no interior de seu território e, em áreas remotas, gerando processos infraestruturais também nessas regiões. A coleta, armazenamento, organização, processamento e distribuição dos dados em torno do SISFRON gera a necessidade de uma ligação de infraestrutura tecnológica, como apontado na seção anterior, e que terão um efeito multiplicador, seja na redução da criminalidade nos centros urbanos, na garantia da soberania e no uso dessas tecnologias empregadas nos demais setores da sociedade.

A importância da infraestrutura pode ser destacada em todas as ações necessárias à atuação do SISFRON: garantia do fluxo ágil e seguro de informações confiáveis e oportunas, prover com estruturas físicas e lógicas adequadas ao ciclo de comando e controle, com capacidade de transmissão compatível com a missão e possibilidade de operar em rede, gerar capacidades operacionais necessárias para responder prontamente a qualquer ameaça ou agressão, dotando-o de meios de mobilidade tática e de apoio logístico adequado aos diversos ambientes operacionais e preparar o combatente da força terrestre para operar em ambiente de alta complexidade com consciência situacional (Barbosa 2014: 65). Assim, em uma primeira etapa há o sensoriamento, depois o processamento, comparação e decisão, fornecendo apoio e subsídios à decisão e, por fim, a ação de repressão em si, por meio dos atuadores (Barbosa 2014: 64).

O SISFRON é um modelo inédito de proteção das fronteiras e prevê uma engenhosa estrutura militar e civil que versará sobre defesa, segurança, desenvolvimento econômico e social (Brasil, Ministério da Defesa 2015). Permite a interoperabilidade entre as Forças Armadas e a troca de informações entre os países vizinhos promovendo cooperação, além disso, permite a integração das agências governamentais nacionais, seguindo a ideia de operações interagências. ${ }^{6}$ Desta forma, além de ampliar e consolidar o trinômio de capacidade de monitoramento, mobilidade e presença na faixa de fronteira, o Sistema promoverá uma maior integração regional, entre órgãos de governo e também com países vizinhos.

\section{CONSIDERAÇÕES FINAIS}

A partir do exposto, depreende-se a importância dos projetos de infraestrutura regional para monitorar e combater os ilícitos na América do Sul. Resumidamente, o artigo apresentou a complexidade dos desafios 
securitários na região da faixa de fronteira para o Brasil. Essas questões demandam soluções variadas, que permitam a integração das forças e de sistemas de defesa. A região se caracteriza por um elevado grau de crimes relacionados com o tráfico internacional de armas e drogas, cuja dinâmica das fronteiras sul-americanas muitas vezes facilitam o processo. Nesse sentido, a falta da presença do Estado, combinada com regiões pobres e sem acesso ao desenvolvimento, de certa forma estimulam o funcionamento dessa economia ilegal.

Dessa forma, a infraestrutura aparece como elemento central para a reversão desse quadro, visto que, além de alavancar o desenvolvimento, o emprego e a renda na faixa de fronteira, o acesso à infraestrutura é pré-requisito para o bom funcionamento de instituições públicas e presença militar para a defesa da região. Afinal, viabiliza a atividade econômica e, de modo dual, também favorece a projeção de força.

Cabe destacar que a compreensão das dinâmicas securitárias regionais envolve a avaliação acerca da correlação entre subdesenvolvimento e fortalecimento das atividades criminosas. Por essa razão, a construção da defesa regional compreende iniciativas multidimensionais; ou seja, que possam mitigar os desequilíbrios sociais e ao mesmo tempo fortalecer os aparatos securitários dos países da região. Disso decorre a importância de projetos como o SISFRON, afinal trata-se de um projeto capaz de gerar transbordamento para outros segmentos além da defesa.

Contudo, a construção da estabilidade regional não pode ficar atrelada apenas a projetos vinculados ao Brasil. Nesse sentido, para que a integração regional possa ser consolidada, é preciso que todos os Estados da região estejam vinculados igualmente ao processo de defesa. Além disso, visto que o projeto integracionista não representa um consenso entre as elites internas de cada país, ressalta-se que o atual momento de turbulência política que se alastra pelo subcontinente tende a abalar a continuidade da cooperação regional. Portanto, é notável que os projetos de infraestrutura dual são indicadores relevantes para se compreender o perfil de integração regional que vem sendo incentivado, especialmente ao se tratar de uma questão tão sensível à região como são os ilícitos transfronteiriços.

\section{REFERÊNCIAS}

Barbosa, C. G. 2014. O Sistema Integrado de Monitoramento de Fronteiras: uma ferramenta de cooperação regional. Anais do I Congresso Brasileiro de Geografia Política, Geopolítica e Gestão do Território, Rio de Janeiro. Rio de Janeiro: REBRAGEO, 843-852. 
Brasil, Ministério da Defesa. 2015. SISFRON atua na defesa e no desenvolvimento da fronteira terrestre do Brasil. Disponível em: http://www.defesa.gov.br/ noticias / 17674-sisfron-atua-na-defesa-e-no-desenvolvimento-da-fronteira-terrestre-do-brasil. Acesso em: 20 nov 2015.

2014. Primeira unidade do Sistema de Monitoramento de Fronteiras entra em funcionamento no Mato Grosso do Sul. Disponível em: http://www.defesa.gov. $\mathrm{br} /$ noticias/14248-primeira-unidade-do-sistema-de-monitoramento-de-fronteiras-entra-em-funcionamento-no-mato-grosso-do-sul. Acesso em: 10 nov 2015.

2008. Estratégia Nacional de Defesa. Brasília.

Brasil, Exército Brasileiro. 2014. Projeto Piloto do SISFRON apresenta os primeiros resultados. Canal Youtube. Disponível em: https://www.youtube.com/watch?v $=$ deI $73 \mathrm{mf} 1 \mathrm{qWY}$ \&index = 17\&list=WL. Acesso em: 07 nov 2015.

Brasil. Presidência da República. 2008. Decreto $n^{\circ} 6.592$ de 2 de outubro de 2008: dispõe sobre a mobilização nacional e cria o Sistema Nacional de Mobilização (SINAMOB). Brasília.

Carvalho, C. H. L. de. 2011. A Integração Sul-Americana e a Mobilização Nacional. Caderno de Estudos Estratégicos de Logística e Mobilização Nacional, 1 (3): 66-80.

Comissão Econômica para a América Latina e o Caribe (CEPAL). 2012. UNASUL: infraestrutura para a integração regional. Santiago do Chile: CEPAL.

Couto, L. F. 2013. Desenvolvimento, Integração e Assimetrias: caminhos e descaminhos da aproximação regional na América do Sul. Brasília: Fundação João Mangabeira.

CPI das Armas. 2006. Comissão Parlamentar de Inquérito destinada a investigar as Organizações Criminosas do Tráfico de Armas. Relatório. Brasília.

Dreyfus, P. 2009. Vino viejo en odres todavía más viejos: tendencias regionales del crimen organizado en Latinoamérica en la primera década del siglo XXI y más allá. In: Mathieu, H., Arredondo, P. R. (Ed.). Anuario 2009 de La Seguridad Regional en América Latina y El Caribe. Bogotá: Friedrich Ebert Stiftung.

Leopoldino, C. M. 2013. Operações Interagências na Faixa de Fronteira e Relações Internacionais. Ministério das Relações Exteriores. Disponível em: http://www. eceme.ensino.eb.br/congressocienciasmilitares/docs/Op\%20Interagencias\%20 na\%20Faixa\%20de\%20Fronteira\%20e\%20Relacoes\%20Internacionais\%20-\%20 Apresentacao\%20CML.pdf Acesso em: 05 dez 2015.

Leite, A. P. 2013. O projeto piloto do sistema integrado de monitoramento de fronteiras: concepção e situação atual. Monografia. Escola Superior de Guerra. 
Masón, A. 2000. La Crisis de Seguridad en Colombia: Causas y Consecuencias Internacionales de un Estado en vía de Fracaso. Colombia Internacional, 49-50.

Oliveira, C. S. de. 2014. O Exército Brasileiro e as Políticas Públicas na Faixa de Fronteira da Região Amazônica Brasileira. In: Hahn, M. G., Martins, J. M. Q., Oliveira, L. K. (Org.). I Seminário Casas de União: Políticas Públicas e Regiões de Fronteira. Porto Alegre: ISAPE.

Pereira, P. J. dos R. 2013. Crime Transnacional na América do Sul: identificação e combate. Anais do $4^{\circ}$ Encontro Nacional da Associação Brasileira de Relações Internacionais. Belo Horizonte: ABRI.

Sain, M. F., Games, N. R. 2014. Tendências e desafios do crime organizado na América Latina. In: Nasser, R. M., Fracalossi de Moraes, R. (Org.). O Brasil e a segurança no seu entorno estratégico: América do Sul e Atlântico Sul. Brasília: Ipea.

UNODC. World Drug Report. 2013. Disponível em: http://www.unodc.org/unodc/secured/wdr/wdr2013/World_Drug_Report_2013.pdf. Acesso em: 10 nov 2015.

Vaz, A. C. 2002. Desafios e Questões de Segurança nas Relações do Brasil com os Países Andinos. Center for Hemispheric Defense and Security Studies (REDES). Panel on Las Seguridades Emergentes de la Comunidad Andina y MERCOSUR. Research and Education in Defense and Security Studies, Brasília, Brasil.

Proença Jr., D., Duarte, É. E. 2005. The Concept of Logistics Derived from Clausewitz: all that is required so that the fighting force can be taken as a given. The Journal of Strategic Studies, 28 (4): 645-677. 


\section{NOTAS}

1. Faixa de até cento e cinquenta quilômetros de largura, ao longo das fronteiras terrestres, e corresponde a $27 \%$ do território. Definição presente na Constituição Federal, além de ser considerada fundamental para defesa do território nacional, a sua ocupação e utilização serão reguladas em lei (Brasil, Constituição Federal, 1988, art. $20^{\circ}, \S 2$ ).

2. Para destacar alguns exemplos da magnitude dos dois principais ilícitos sul-americanos: calculam-se que existam cerca de 140 pontos de entrada de contrabando de armas no Brasil (CPI Tráfico de Armas 2006: 394). "Em 2011, mais da metade da cocaína apreendida no Brasil tinha origem na Bolívia (54\%), seguida pelo Peru (38\%) e Colômbia (7,5\%)" (UNODC, World Drug Report 2013: 41), sendo que os três maiores produtores mundiais de cocaína fazem fronteira com o Brasil: Peru, Colômbia e Bolívia.

3. Tanto o aumento na quantidade de infraestrutura (mais estradas, mais portos, etc.), assim como o aumento da sua qualidade (reformas, modernizações) geram impactos positivos sobre o crescimento econômico e sobre a distribuição de renda.

4. O Plano Estratégico de Fronteiras configura-se através de "operações integradas entre os órgãos de segurança pública e as Forças Armadas para prevenir e reprimir ilícitos transnacionais" (LBDN 2012: 179). O Plano foi criado pelo Decreto $n^{\circ} 7.496$ de junho de 2011, com os objetivos de neutralização do crime organizado, redução dos índices de criminalidade, cooperação com os países fronteiriços e apoio à população na faixa de fronteira - essa iniciativa por si só já demonstra que essas novas questões de segurança geram preocupação ao Brasil.

5. Ressalta-se que o SISFRON ambiciona ser o maior sistema integrado de vigilância de fronteiras do mundo e deverá tornar permanente o caráter das operações Ágata e Sentinela. Foi orçado em 12 bilhões, sendo que desse valor mais de $70 \%$ deve ser contratado internamente. Será um mecanismo para angariar novas oportunidades de cooperação bilateral e regional, além de abrir a possibilidades de exportação de produtos e serviços (Leopoldino 2013).

6. O SISFRON, a despeito do que alguns críticos afirmam, não se pretende um muro virtual para separar o Brasil dos países vizinhos, ao contrário, é um modelo que pode vir a ser empregado nos demais países e que permite a cooperação e o compartilhamento de dados, como rotas e periodicidade. O Sistema deve vir acompanhado de ações no plano político, a fim de dirimir qualquer desconfiança entre os vizinhos e deve ser tratado com transparência. A integração infraestrutural nessas re- 
giões, para a completa instalação do SISFRON, além de gerar inclusão digital para os brasileiros que vivem nessas áreas, também pode ser expandido para os países vizinhos, que, nas áreas de fronteira, possuem os mesmos déficits estruturais que o Brasil, através de acordos de cooperação técnica e monitoramento conjunto. 


\section{RESUMO}

Esse artigo trata do papel da infraestrutura, especialmente a de comunicações, no combate e monitoramento dos ilícitos transfronteiriços na América do Sul. A partir do panorama dos ilícitos regionais, analisa-se como a infraestrutura pode ser decisiva para garantir a segurança regional, com efeitos para o desenvolvimento e a integração.

Palavras-chave: Infraestrutura; Ilícitos Transfronteiriços; América do Sul; SISFRON.

\section{ABSTRACT}

This paper deals with the role of infrastructure, especially communications, in combating and monitoring cross-border illegal activities in South America. From the regional panorama of illicit crimes, it is show how the infrastructure can be decisive in ensuring regional security, with effects on the development and integration.

Keywords: Infrastructure; Cross-border illicit; South America; SISFRON. 